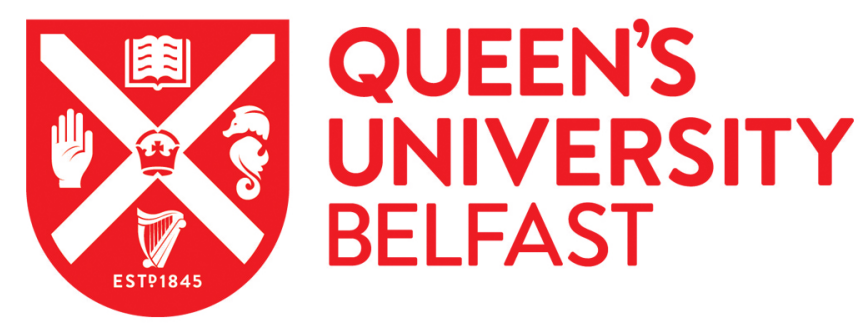

\title{
Imagining their future selves: Children's attitudes to older people and their expectations of life at age 70
}

Lloyd, K., Devine, P., \& Carney, G. M. (2018). Imagining their future selves: Children's attitudes to older people and their expectations of life at age 70. Children and Society, 32(6), 444-456. https://doi.org/10.1111/chso.12289

\author{
Published in: \\ Children and Society
}

\section{Document Version:}

Peer reviewed version

Queen's University Belfast - Research Portal:

Link to publication record in Queen's University Belfast Research Portal

\section{Publisher rights}

Copyright 2018 Wiley. This work is made available online in accordance with the publisher's policies. Please refer to any applicable terms of use of the publisher.

\section{General rights}

Copyright for the publications made accessible via the Queen's University Belfast Research Portal is retained by the author(s) and / or other copyright owners and it is a condition of accessing these publications that users recognise and abide by the legal requirements associated with these rights.

Take down policy

The Research Portal is Queen's institutional repository that provides access to Queen's research output. Every effort has been made to ensure that content in the Research Portal does not infringe any person's rights, or applicable UK laws. If you discover content in the Research Portal that you believe breaches copyright or violates any law, please contact openaccess@qub.ac.uk. 
Imagining their future selves: Children's attitudes to older people and their expectations of life at age $\mathbf{7 0}$

Author 1: Katrina Lloyd, PhD*.

School of Social Sciences, Education and Social Work

Queen's University Belfast

Belfast

BT7 1NN

Email: k.lloyd@qub.ac.uk

Telephone: 02890975962

Author 2: Paula Devine, PhD.

ARK

School of Social Sciences, Education and Social Work

Queen's University Belfast

Belfast

BT7 1NN

Author 3: Gemma M. Carney, PhD.

School of Social Sciences, Education and Social Work

Queen's University Belfast

Belfast

BT7 1NN

The module on ageing was funded by Improving Children's Lives, Queen's University

Belfast. The authors would like to acknowledge the schools and children who participated in the 2014 Kids' Life and Times survey.

The authors report that there are no conflicts of interest relating to this paper. 
Imagining their future selves: Children's attitudes to older people and their expectations of life at age $\mathbf{7 0}$

\begin{abstract}
Studies eliciting the views of children on ageing are rare, particularly those that focus on imagining a future self as an 'old' person and how this might be linked to current attitudes to older people. To address this gap, 2365 children participated in an online survey which included questions on ageing. Findings suggest that children who hold negative views about old people visualise poorer outcomes for themselves at age 70. Implications of the findings are discussed in the context of an ageing population and the need to develop strategies to prevent the formation of prejudices against older people from an early age.
\end{abstract}

Key words: Children, Attitudes, Ageism, Health, Wellbeing 


\section{Imagining their future selves: Children's attitudes to older people and their expectations of life at age $\mathbf{7 0}$}

\section{Introduction}

According to the United Nations (2015) almost every country in the world is experiencing a growth in the proportion of older people; by 2020 those aged 65 years and over will outnumber children under the age of five ( $\mathrm{He}$, Goodkind and Kowal 2016). Many of the implications of this growth in the number of older people, particularly on the lives of younger cohorts, have been well rehearsed in the media (e.g. BBC 2016) and in academic research (Bloom et al 2015; Robinson and Howatson-Jones 2014). Robinson and Howatson-Jones (2014) suggest that ageing populations mean increased health and social care costs, the responsibility of which will fall to the younger generations 'making intergenerational understanding and support an urgent issue' (pg 294). However, given Palmore's contention that ageism (holding negative attitudes towards older people) 'is so much a part of our culture that most people are not even aware of it' (2015, pg 874), fostering this understanding and support for older people among the young may be challenging to achieve.

One difficulty is that children may be unable to empathise with older people as they are clearly a long way from this stage of their own lives. However, a promising approach in researching intergenerational relations from the perspectives of children comes from investigations focused on asking individuals to visualise their future selves (Elliott 2010; Jarrott and Savla 2016; Russell, Alexis and Clayton 2009) - in 
effect to put themselves in 'the position of a person of another age, the age-other' (Biggs and Lowenstein 2011, pg 1107).

Studies which set out to elicit the views of young children on ageing are rare (Settersten 2005), particularly those with a focus on imagining a future self as an 'old' person and how this might be linked to current attitudes to older people. Our paper seeks to address this gap using quantitative and qualitative responses to questions on ageing included in a large-scale survey of 10 or 11-year-old children. The overall aim of the study is to seek children's current views about old people and explore the potential influence this may have on their visualisations of their future selves at age 70 .

\section{How old is old?}

According to Levy and Macdonald (2016) age is a social construction and people have different notions of 'old age' depending on their own age. Evidence for this comes from research with adults and children (Devine and Carney 2015; Davidovic et al 2007). In a review of literature on children's attitudes towards ageing, Robinson and Howatson-Jones (2014) found that the majority define 'old' as older than 60 years. Taken together, research findings confirm that notions of 'old age' are relative and suggest that studies which ask people to visualise themselves as 'old' should tell participants which age range or actual age to think of - something identified recently by Levy and Macdonald (2016). When asked to visualise their future selves, the children in the current study were asked to imagine what they would be doing when they were 70 years - an age that marks a period of retirement and leisure for many 
of today's generation but, potentially, not for their future counterparts (Macnicol 2015).

\section{Children's attitudes to older people}

One early example of research on children's attitudes towards older people is the work of Seefeldt et al. (1977) who administered the Children's Attitudes Toward the Elderly instrument to 180 children aged 3 to 11 years. The findings were complex, and mostly negative and stereotypic. The general view about older people, expressed by participants, was as sick, tired and ugly, and they expressed disgust at the thought of growing old themselves. Conversely, the children had strong affective feelings towards older people, describing them as wonderful, kind and rich. In their review of the literature, Murphey and Myers (1982) found that children have little knowledge of, or contact with, older persons and that their perceptions of ageing are generally negative. In contrast, both Thompson and Weaver (2016) and Jarrott and Savla (2016) found that young people hold both positive and negative views of ageing and older people. The latter suggest ambivalence can be healthy as it reflects 'diverse experiences related to aging and older adults' (Jarrott and Savla 2016, pg 283) and may allow for the development of positive coping strategies for later life.

Robinson and Howatson-Jones (2014) undertook international literature-based research to identify what is known about children's views of older people and concluded that while children did not appear to be ageist they did adopt stereotypes of older people (beliefs about older people in general). This fits with the 'stereotype embodiment' theory developed by Levy (2009, pg 332) who proposes that stereotyping of older people begins in childhood. Levy speculates that if these 
stereotypes become internalised in childhood, and continue across the lifespan, they may have detrimental effects on the self-perceptions of older people and on their health and wellbeing outcomes. Furthermore, Ramırez and Palacios-Espinosa (2016) reported that negative stereotyping was related to a greater concern with ageing among adults aged over 44 years. They also found some evidence that current perceptions of mental and physical health are related to ageing anxiety. If age stereotyping does begin in childhood then it could be that children's views about their own ageing may be influenced by their current attitudes - positive or negative towards older people. One way to test this theory is to elicit the views of children on older people and on their own prospective ageing. Current thinking on this approach is explored in the following sections.

\section{Constructing an imagined future as an 'old person'}

According to Tulving (2005) human beings possess the ability to mentally travel through time while remaining in the present. One aspect of this is to envision the future - something which he argues is evident from childhood through to old age. That children, as well as adults, can imagine the future has been demonstrated by researchers across a range of contexts including work orientations (Laurie 2010), children's anticipated lives at the age of 25 (Elliott 2010) and game-playing among three, four and five year old children (Russell et al 2009). Taken together, these studies suggest that, by the age of five years, children are able to imagine their 'future selves'.

However, none of these studies asked the children to imagine themselves as 'old' people, something that was done by Jarrott and Savla (2016). They asked students 
to imagine themselves as older people and explored the relationship between their feelings towards getting old and a range of variables including intergenerational contact, anxiety, knowledge and empathy. The authors found that higher ratings of intergenerational contact, lower ageing anxiety, and higher empathy predicted lower ageing self-ambivalence, which they contend reflected positive expectations for later life among the young people in their research (Jarrot and Savla 2016). This study demonstrates that young people's current feelings and experiences of older people appear to influence their perceptions of how they feel about getting older themselves. While it is clear that these young people are a long way from being old themselves, nonetheless, they have the ability to put themselves in what Biggs and Lowenstein (2011, pg 1107) describe as 'the position of a person of another age, the age-other'. This is a key dimension of the model of intergenerational relationships developed by these authors and which they term 'generational intelligence' (Biggs and Lowenstein 2011, pg 1107). They describe generational intelligence as an awareness of oneself as part of a generation but with the relative ability to put oneself in the position of other generations.

In an attempt to understand children's imagined futures, the idea of generational intelligence is useful as it allows an interpretation of children's presented views of their own generational status and the extent to which they can imagine their 'ageother.' The main aim of this paper is to seek children's current views of older people and explore the potential influence these may have on their imagined future lives at age 70 through the lens of the generational intelligence theory proposed by Biggs and Lowenstein (2011). Based on the work of Jarrott and Savla (2016) with undergraduate students, it is expected that children who hold negative views of older 
people at the age of 10 or 11 years will have less positive visualisations of their lives at age 70 than their peers who hold more positive views. The paper also considers whether, and how, imagined futures are related to the children's current subjective health and wellbeing (Ramırez and Palacios-Espinosa 2016).

\section{Method}

\section{Design and participants}

The data for this paper came from a large-scale online survey of children aged 10 or 11 years carried out annually in schools in Northern Ireland - Kids' Life and Times $(\mathrm{KLT})$. The survey is anonymous and consists of questions on topics relevant to the lives of children, including attitudes to school, bullying and wellbeing. In each year approximately 5,000 children participate in KLT. In 2014, which was a split survey meaning that half of the sample were asked about ageing and older people, 2,365 children ( $49 \%$ girls, $51 \%$ boys) responded to these questions.

\section{KLT Questionnaire}

The questionnaire consists of around 80 questions and respondents click on the answer that best applies to them. Core questions, including sex, subjective health and wellbeing are asked in each year of the survey while modules of questions, such as bullying and Children's Rights, are purchased by funders within particular years. In 2014, a module on attitudes to ageing was included in KLT. The questions were designed by researchers from the ARK (Access, Research, Knowledge) Ageing Programme, which focuses on what it means to grow older. The inclusion of questions in the KLT survey reflected a general lack of information on the views of 
children about older people and getting older themselves, not only in Northern Ireland but elsewhere (Settersten 2005).

\section{Instruments}

Attitudes to ageing

The analyses for the paper are based on six questions from the ageing module. Respondents were asked 'At what age do you start to think of an adult as an old person?' with responses recorded in years. Perceptions of older people were assessed using four items designed for KLT (mobility, generosity, memory, independent living) and were based on common stereotypical attributes assigned to older people in the media (Robinson, Gustafson and Popovich 2008) and held by people in the population more generally (WHO 2017). Each item provides the respondent with four possible answers. For example, item 1 (mobility) has the responses: They can move around quickly (1); They can move around fairly quickly (2); They are a bit slow (3); They are slow and hold other people up (4). The items were reverse coded and summed to create an attitude scale ranging from 4 (negative attitudes) to 16 (positive attitudes). Cronbach's alpha, measuring scale reliability, is 0.50 which is below the recommended threshold of 0.70 . However, we feel that this is an acceptable level for two reasons. Firstly, the scale contains only four items which can adversely affect the reliability (Tavakol and Dennick 2011) and, secondly, the scale was created to facilitate analysis of the responses with those from an open-ended question on children imagining their futures. This question 'What do you think you will be doing when you are aged 70?' prompted the children to adopt the position of the 'age-other' rather than reporting what they, as children, think about older people. 
Wellbeing

Children's subjective wellbeing was assessed using KIDSCREEN-10 which is designed for use with children aged eight years and over (Higher scores on the KIDSCREEN-10 indicate better wellbeing. The scores that are presented in this paper are the international T-values (Mean=100; SD=50). Internal consistency of the KIDSCREEN-10 for this sample of children, measured using Cronbach's alpha, was .76 which indicates the questionnaire has good reliability.

\section{Physical Health}

The children were asked one question about their health 'In general, how would you say your health is?' 'Poor; Fair; Good; Very Good; Excellent'. For ease of analysis, and due to the relatively small number of children who said their health was 'poor' (57 respondents), the responses were recoded into three categories: Excellent/Very good; Good; Fair/Poor.

\section{Procedure}

Each year, all primary school principals in Northern Ireland are sent letters, parental consent forms, teacher instructions and bookmarks for Primary 7 pupils (who are in their final year of primary (elementary) school) in the weeks prior to KLT going live on the internet. All P7 pupils are invited to participate along with home-schooled children and those who have been excluded from school. Parents of home-schooled children are sent the information through the Education Authority in Northern Ireland. Respondents are not asked for their names, so it is not possible to identify individual pupils; only a school identification number is required to log on to the survey. Respondents complete the questionnaire on computers in their school. Each 
question has a skip option which the respondents can use if they do not want to answer a question. The survey takes about 20 minutes to complete. Details of the survey are available at www.ark.ac.uk/klt

\section{Ethics}

Ethical approval was given for KLT by the Ethics Committee in the School of Sociology, Social Policy and Social Work at Queen's University Belfast. Children can only take part in the survey if their school principals and their parents/guardians give their consent. At the start of the survey, the children are asked if they want to participate in KLT and, if not, they do not have to.

\section{Data analysis}

Descriptive statistics are presented and chi-squared analyses, ANOVA and independent t-tests are used to explore differences between children in relation to their attitudes to old people and to their visualisations of their future selves. Given that this is a large sample, effect sizes are presented along with statistical significance to ensure the practical significance of the findings is clear. The openended question 'What do you think you will be doing when you are aged 70?' was analysed using a content analysis approach which involved devising a coding frame to describe the thematic content of the children's comments. Following the coding of these verbatim responses into a relatively small set of categories, a new variable was created in the dataset (Lavakas 2008; O'Cathain and Thomas 2004). Two overarching themes emerged as a result of the coding process: 'Cosy' or positive responses such as being happy, healthy and living comfortably at home with their family and 'Frail' or negative responses focusing on being ill, needing care or being 
dead. The remainder were coded 'don't know'. Therefore the re-coded variable had three categories - Cosy/Positive, Frail/III/Dead and Don't know.

\section{Results}

\section{When does old age begin?}

The KLT survey respondents were first asked at what age they start to think of an adult as old, and the responses varied considerably - some thought 30 was old while the maximum age recorded was 101 years. The mean age considered as being old by these 10 or 11 year olds was 54 years which is somewhat younger than the figure of 60 years reported by Robinson and Howatson-Jones (2014).

Many children taking part in KLT gave precise ages, whilst others rejected the idea that an exact age could be specified:

‘60-65 depending on their abilities and appearance.'

'I don't really like to think of anyone being old. If I had to say l'd probably say when the adult is in his/her 50's/60's.'

Some respondents explained their responses:

'I think at about 60 years old because you start to get more wrinkly.'

'When they hit the age 60 and above $u$ would need to help them out with stuff.'

Other children acknowledged that 'age is just a number':

'I don't think of them as old people.'

'I just think of them as people that have lasted longer.' 
Overall then, it is clear from these findings that $\mathrm{KLT}$ respondents have mixed views on the concept of what is 'old' with some identifying an actual age and others associating ageing with stages, for example when people get wrinkles or need help.

\section{Children's attitudes towards older people}

Table 1 presents the responses to the questions exploring children's ratings of the capabilities of old people they 'see or know'. Respondents were most 'negative' in terms of older people's mobility, followed by their ability to live independently. Conversely, there was overwhelming support for the idea that old people are generous. Opinion was more split in terms of memory; 17 percent thought that old people have a really good memory and a further 26 percent thought that old people remember most things. However, 39 percent thought that old people are a bit forgetful, and six percent would describe old people as really forgetful. These findings offer support for Jarrott and Savla (2016) and Thompson and Weaver (2016), and show that KLT respondents appear to hold a mix of both positive and negative views about older adults. 
Table 1: Attitudes towards old people children see or know (\%)

\begin{tabular}{|c|c|c|c|c|c|}
\hline $\begin{array}{l}\text { They are } \\
\text { slow, and } \\
\text { hold other } \\
\text { people up }\end{array}$ & $\begin{array}{l}\text { They are a } \\
\text { bit slow }\end{array}$ & $\begin{array}{l}\text { They can move } \\
\text { around fairly } \\
\text { quickly }\end{array}$ & $\begin{array}{l}\text { They can } \\
\text { move } \\
\text { around } \\
\text { quickly }\end{array}$ & $\begin{array}{l}\text { Can't } \\
\text { choose }\end{array}$ & \\
\hline 7 & 50 & 16 & 7 & 21 & $\begin{array}{l}\text { (Mobility) } \\
N=1814\end{array}$ \\
\hline $\begin{array}{c}\text { They cannot } \\
\text { live on their } \\
\text { own }\end{array}$ & $\begin{array}{c}\text { They can } \\
\text { live on their } \\
\text { own, but } \\
\text { need a lot of } \\
\text { help }\end{array}$ & $\begin{array}{l}\text { They can live } \\
\text { on their own, } \\
\text { but need a bit } \\
\text { of help }\end{array}$ & $\begin{array}{c}\text { They can } \\
\text { live on their } \\
\text { own }\end{array}$ & $\begin{array}{c}\text { Can't } \\
\text { choose }\end{array}$ & \\
\hline 5 & 8 & 48 & 23 & 15 & $\begin{array}{c}\text { (Independent } \\
\text { living) } \\
\mathrm{N}=1933\end{array}$ \\
\hline $\begin{array}{c}\text { They are } \\
\text { really selfish }\end{array}$ & $\begin{array}{c}\text { They are a } \\
\text { bit selfish }\end{array}$ & $\begin{array}{c}\text { They are quite } \\
\text { generous }\end{array}$ & $\begin{array}{c}\text { They are } \\
\text { really } \\
\text { generous }\end{array}$ & $\begin{array}{c}\text { Can't } \\
\text { choose }\end{array}$ & \\
\hline 1 & 2 & 19 & 68 & 11 & $\begin{array}{c}\text { (Generosity) } \\
N=2051\end{array}$ \\
\hline $\begin{array}{l}\text { They are } \\
\text { really } \\
\text { forgetful }\end{array}$ & $\begin{array}{l}\text { They are a } \\
\text { bit forgetful }\end{array}$ & $\begin{array}{l}\text { They } \\
\text { remember } \\
\text { most things }\end{array}$ & $\begin{array}{c}\text { They have a } \\
\text { really good } \\
\text { memory }\end{array}$ & $\begin{array}{c}\text { Can't } \\
\text { choose }\end{array}$ & \\
\hline 6 & 39 & 26 & 17 & 11 & $\begin{array}{l}\text { (Memory) } \\
\mathrm{N}=2032\end{array}$ \\
\hline
\end{tabular}

\section{Children imagining their future lives}

To set the context for exploring the potential influence of the children's current attitudes towards older people on their imagined futures, some preliminary quotes from the open-ended question 'What do you think you will be doing when you are aged 70?', to which 2075 children responded, are presented. In line with the 
quantitative data, the children's open-ended responses reflected a range of both positive and negative views. For some children, there was an emphasis on frailty, and many referred to the need to move to a care home, being ill, dying, or being dead:

'In hospital with fractured arms and legs.'

'I would be forgetting everything, I would be getting depression'.

'Getting ready to die, and will be planning my funeral.'

'In a hospital bed or lying in a coffin.'

In contrast, other children had a positive vision of life at age 70 and there was a strong focus on comfort, retirement and home. Many children clearly have an expectation that they will enjoy a leisurely retirement:

'Loving life.'

'Probably on the verge of retirement after a well-spent life with adventures and accomplishment.'

'Living with my husband in a nice cosy flat and my children and grandchildren visiting me every weekend.'

Others envisioned a life where they would still be fit and healthy and, possibly, working:

'Still exercising and not letting my age slow me down.'

'Going to old people gym classes'.

'Still working as a teacher coming to retirement soon.' 
Indeed one child displayed a high level of knowledge of the policy context in relation to work and retirement: 'The law won't let you retire until you are 67 now so by the time I am 67 the number will have increased so probably still working.'

Based on the three-way classification created from the open-ended responses, the majority of children (64\%) were positive about their future at age 70 (Cosy/Positive), with 16 percent giving responses that reflected negative visualisations (Frail/III/Dead). One in five children said they did not know what they would be doing at age 70 . How these classifications relate to the children's current perceptions of old people is presented in the following section.

\section{Relationship between current perceptions and visualising life at age 70}

To test the main premise of the paper, which is that children's current perceptions of older people will influence their own imagined future lives, we divided the scores on the attitude scale into three groups (negative, mixed and positive). In order to identify the cut-off points for each group, we created a histogram of the respondents' scores on the scale. From this, we identified approximately three divisions: children with scores between 4 and 10 were deemed to hold the most negative views of older people $(23 \%$; $N=316)$; those with a score of 11 or 12 were deemed to hold mixed views (45\%; $N=642)$, while respondents with scores from 13 to 16 were considered to hold more positive views of older people (32\%; $\mathrm{N}=447)$. Table 2 indicates that children who had more negative attitudes towards older people were most likely to imagine that they would be frail, ill or dead when they were aged 70 years (63\%).

Conversely, it was children defined from the attitude scale as having mixed perceptions of old people who were most likely to have positive predictions for their 
future old age (71\%), followed by children with positive attitudes $(67 \%)$. While the difference across groups was statistically significant $\left(X^{2}=15.77, d f=4, p<0.005\right)$, the effect size was small (Cramer's $V=0.07$ ). Overall therefore, there is some support from KLT that children who feel more negative about old people at age 10 or 11 years are also more likely to envision a poor outcome for themselves at age 70.

Table 2: Visualisation of life aged 70, by attitudes towards older people

\begin{tabular}{|l|c|c|c|}
\hline & \multicolumn{3}{|c|}{ Attitudes towards old people } \\
\hline Visualisation of life at age 70 & Positive & Mixed & Negative \\
& $\%$ & $\%$ & $\%$ \\
\hline Cosy/Positive & 67 & 71 & 63 \\
\hline Frail/III/Dead & 15 & 14 & 24 \\
\hline Don't Know & 18 & 15 & 14 \\
\hline Total & $100(\mathrm{~N}=447)$ & $100(\mathrm{~N}=642)$ & $100(\mathrm{~N}=316)$ \\
\hline
\end{tabular}

\section{Visualisation of life at 70 by current subjective health and wellbeing}

In order to explore whether children who imagined a negative outcome at age 70 differed from the children who envisioned a more positive or mixed future for themselves, further analyses were carried out using variables which were included in the KLT survey. The choice of variables was based on studies with adults (e.g. Ramırez and Palacios-Espinosa 2016) suggesting that current perceptions of mental and physical health are linked with ageing anxiety among adults.

Table 3 shows that children who perceived their physical health as excellent/very good were more positive than those who rated their health as good and, particularly, those who thought their health was fair or poor. However, while the differences were statistically significant $\left(x^{2}=19.29, \mathrm{df}=4, \mathrm{p}<0.005\right)$, the effect size was small (Cramer's 
$V=0.07)$. Similarly, there was a statistically significant effect of visualisations for the future on children's wellbeing assessed using the KIDSCREEN-10 ( $F=8.11$, $d f=2,2045, p<0.001)$. Post hoc ${ }^{i}$ comparisons between the three groups indicated that the mean wellbeing score for children who had negative visualisations of the future was significantly different from their peers who had more positive views or who said they did not know; however, the latter two groups did not differ significantly from each other. The results suggest that it is the children who have negative visualisations of their lives at the age of 70 who have the poorest wellbeing when compared with those who have positive visualisations or who say they don't know what they will be doing at the age of 70 years.

Table 3: Visualisation of life at 70 by health and wellbeing

\begin{tabular}{|l|c|c|c|c|}
\hline \multicolumn{4}{|c|}{ Visualisation of life at age 70 } \\
\hline Characteristics & $\begin{array}{c}\text { Cosy/Positive } \\
\%\end{array}$ & $\begin{array}{c}\text { Frail/Il/Dead } \\
\%\end{array}$ & $\begin{array}{c}\text { Don't Know } \\
\%\end{array}$ & $\begin{array}{c}\text { Total } \\
\%\end{array}$ \\
\hline Physical Health* & & & & \\
Excellent/Very good & 66 & 15 & 19 & 100 \\
Good & 60 & 20 & 20 & 100 \\
Fair/Poor & 53 & 28 & 19 & 100 \\
\hline Wellbeing* & Mean (sd) & Mean (sd) & Mean (sd) & \\
& $50.23(8.96)$ & $48.00(9.94)$ & $50.15(9.30)$ & \\
& $\mathrm{N}=1312$ & $\mathrm{~N}=336$ & $(\mathrm{~N}=400)$ & \\
\hline
\end{tabular}

${ }^{*}$ Differences are statistically significant $(p<0.005)$

One final analysis undertaken was to compare the wellbeing of children whose current attitudes towards old people were negative and who foresaw a poor visualisation of their lives at age 70 (negative on both variables) to children with the opposite view i.e. positive attitudes and a good visualisation of the future (positive on 
both variables). While the numbers in the groups were small ( $n=75$ and $n=299$ respectively), nonetheless, the findings are intriguing (Table 4). Children who were negative on both variables had significantly poorer perceptions of their health than those who were positive on both variables $\left(x^{2}=7.96, d f=2, p<0.05\right.$; Cramer's $\left.V=0.15\right)$. In addition, the former had a much lower mean wellbeing score ( $M=46.44 S D=8.89)$ than their counterparts who were positive on both variables $(M=51.24 S D=8.68)$ and this difference was statistically significant $(t=4.21, d f=367, p<0.001)$. The effect size, assessed using Cohen's $d$, was 0.551 which, by convention ${ }^{i i}$, is a medium effect size, suggesting moderate practical significance.

Table 4: Positive and negative attitudes by health and wellbeing

\begin{tabular}{|l|c|c|}
\hline Characteristics & $\begin{array}{c}\text { Positive at age 70 and } \\
\text { positive current attitudes } \\
\%\end{array}$ & $\begin{array}{c}\text { Negative at age 70 and } \\
\text { negative current attitudes } \\
\%\end{array}$ \\
\hline Physical Health* & & 67 \\
Excellent/Very good & 81 & 21 \\
Good & 14 & 12 \\
Fair/Poor & 5 & 100 \\
Total & 100 & Mean (sd) \\
\hline Wellbeing & Mean (sd) & $46.44(8.89)$ \\
& $51.24(8.68)$ & $\mathrm{N}=75$ \\
\hline
\end{tabular}

${ }^{*}$ Differences are statistically significant $(p<0.005)$ 


\section{Discussion}

\section{Children's attitudes to older people}

This study found that many children taking part in KLT held somewhat stereotypical views of old people perceiving them to be a 'bit' slow, a 'bit' forgetful and needing a 'bit' of help to live on their own. Nevertheless, very few were completely negative across the four items and just over two-thirds believed old people are really generous. These findings offer support for previous research and suggest that children's attitudes to old people are complex (Jarrott and Savla 2016; Seefeldt et al 1977) and may reflect children's experiences of contact given that they were asked about old people they 'see or know'. It could also be related to the children's own perception of the age at which a person is 'old' given the diversity of ages reported in KLT by respondents. Overall, the findings from the survey suggest that stereotyping of older people is evident at the age of 10 or 11 years.

\section{Constructing an imagined future as an 'old person'}

When asked what they thought they would be doing at the age of 70 , the majority of KLT respondents were able to envision something they would be doing (Elliott 2010; Laurie 2010; Russell et al 2009; Tulving 2005) with around 20 percent unable or unwilling to do so. This suggests that most of the respondents are exhibiting intergenerational intelligence. While it is clear that they are a long way from being old themselves, like the undergraduates taking part in the Jarrott and Savla (2016) study, it appears that even 10 or 11 year olds have the ability to put themselves in what Biggs and Lowenstein (2011, pg 1107) describe as 'the position of a person of another age, the age-other'. 
For some, being 70 years old meant retirement and relaxation while for others there was a clear vision of still being in employment. However, not all imaginings were positive; a small minority of respondents felt they would be ill, frail or dead at age 70 . Furthermore, children who had negative feelings about old people were also slightly more likely than those with positive or mixed feelings to envision being ill, frail or dead. These findings are important given that longitudinal research with adults aged over 50 years has shown that those with more positive self-perceptions of ageing lived longer and reported better health than those with less positive self-perceptions of ageing (Levy et al. 2002a; Levy et al. 2002b). This prompted us to explore whether children with negative expectations differed in any way from those who envisioned a more positive future for themselves. We found that children who perceived their physical health as excellent/very good were more likely to have a positive visualisation of their lives at the age of 70 compared to children who rated their health as fair/poor - the latter were most likely to envision being ill, frail or dead.

These results offer support for Ramırez and Palacios-Espinosa (2016) who also found evidence that current perceptions of physical health are related to ageing anxiety in adults over the age of 54 years. However, they contrast with the work of Levy et al (2002a) who found that while positive self-perceptions of ageing predicted better health and longevity over time, this was unrelated to baseline evaluations of respondents' functional health. One possible reason for the disparity in findings is that different measures of health were used across the studies. The question used by Ramırez and Palacios-Espinosa (2016) was very similar to ours: 'In general, right now, how is your physical health?' with responses on the same five-point Likert scale as ours, while Levy et al (2002a) asked about physical functioning such as whether 
participants were currently able to walk a mile, or go up and down stairs. In addition, while the results from our study were statistically significant the effect size was small suggesting little practical or real-world significance among this age group of children. Overall, the findings highlight the need for future studies to use more nuanced measures of global health and, particularly among older adults, include measures of physical functioning.

Another finding of particular note to emerge from this research is that children who had negative attitudes towards old people and foresaw a poor visualisation of their future lives at age 70 had lower wellbeing than their peers who had more positive attitudes and visualisation for the future. Given the link between poor current mental health and ageing anxiety among adults reported by Ramırez and Palacios-Espinosa (2016), the results suggest that this relationship could begin early and, if perpetuated over the lifespan, may negatively affect the quality of life that these children experience later in life. Therefore, exploring the ways that children see themselves in the present, and how this relates to their visualisations of their future, might help us to learn how people navigate their way through the (inevitable) ageing process. This aligns with the suggestion by Pinquart et al (2000) that 'interventions to change negative attitudes or to build positive attitudes should begin early' (pg 524).

\section{Limitations}

Despite the important implications of this research to knowledge about children's attitudes towards ageing, there are a number of limitations that need to be addressed in future research. Firstly, there were only four items in the scale created to assess children's perceptions of old people and one question on overall health. 
This was due to space restrictions within KLT which is a general survey of children's attitudes to a range of topics. Future research should include additional questions to provide more nuanced measures of attitudes and health. Secondly, two overarching themes that emerged from the open-ended question on visualising the future, Cosy/Positive and III/Frail/Dead, were used for the analysis in this paper. It may be that using sub-themes such as being fit and healthy, living comfortably, needing care, and being ill may have produced slightly different results. The decision to use the two themes was influenced by the small numbers of responses in some of the sub-themes.

Thirdly, while the open-ended question on visualising the future included a specific age, 70 years, the four attitude questions did not. In line with the suggestion by Levy and Macdonald (2016) this is something that should be done in future studies.

Finally, the KLT survey did not include questions about children's direct contact with older people, such as grandparents, and this should also be addressed in future research.

\section{Conclusion}

Notwithstanding these limitations, the findings from this study are important for several reasons. The first is based on the self-fulfilling principle; insights from social psychology suggest that people's expectations for their future lives are important in shaping and determining their outcomes (Levy 2009; Schafer and Shippee 2010). As Levy (2009) proposed, if negative stereotypes become internalised across the lifespan, they can have detrimental effects on the self-perceptions of future cohorts of older people and on their health and wellbeing outcomes. Secondly, negative 
feelings towards older people are likely to reinforce patterns of age segregation (Hagestad and Uhlenberg 2005). The segregation of different age groups can itself reinforce ageism, and so the cycle continues (Riley and Riley, 2000). The negative stereotyping of older people may also result in further episodes of intergenerational conflict, especially in times of austerity as predicted by Willets (2010). In an effort to avoid this, we agree with Davidovic et al (2007) who suggest the need to develop, and implement, strategies which will help prevent the formation of prejudices against people of different age groups, and older people in particular. The development of meaningful intergenerational encounters and settings is one such strategy which would reduce the institutional, spatial and cultural separation of people of different phases of the life course (Hagestad and Uhlenberg, 2005).

\section{References}

BBC (2016) 'Young suffer as pensioners continue to prosper, says IFS.' [Cited 2018 June 5]. Available from: http://www.bbc.co.uk/news/business-36826166

Biggs, S. and Lowenstein, A. (2011) Generational Intelligence: A critical approach to age relations. London: Routledge.

Bloom, D.E., Chatterji, S., Kowal, P., Lloyd-Sherlock, P., McKee, M., Rechel, B., Rosenberg, L. and Smith, J.P. (2015) Macroeconomic implications of population ageing and selected policy responses. The Lancet, 385 (9968), 649-57.

Davidovic, M., Djordjevic, Z., Erceg, P., Despotovic, N. and Dragoslav P. (2007) Ageism: Does it exist among children? The Scientific World Journal, 7, 1134-1139. 
Devine, P. and Carney, G.M. (2015) Is Northern Ireland a good place to grow old? Research Update 100. ARK: Belfast. [Cited 2018 June 5]. Available from: www.ark.ac.uk/publications/updates/update100.pdf

Elliott, J. (2010) Imagining a gendered future: children's essays from the National Child Development study, Sociology, 44 (6), 1073-1090.

Hagestad, G.O., and Uhlenberg, P. (2005) The social separation of old and young: A root of ageism. Journal of Social Issues, 61, 343-360.

He, W., Goodkind, D. and Kowal, P. (2016) An Aging World: 2015 U.S. Census Bureau, International Population Reports, P95/16-1, U.S. Government Publishing Office, Washington, DC, 2016. [Cited 2018 June 5]. Available from: http://cdn.cnsnews.com/attachments/census bureau-an aging world-2015.pdf Jarrott, S.E. and Salva, J. (2016) Intergenerational contact and mediators impact ambivalence towards future selves. International Journal of Behavioral Development, 40(3): $282-288$

Laurie, H. (2010) Where are they now? Pathways into early adulthood. In Winterton, M., Crow, G., and Graham, B. M. (Eds) Young lives and imagined futures: Insights from archived data. [Cited 2018 June 5]. Available from:

www.timescapes.leeds.ac.uk/assets/files/secondary analysis/working\%20papers/W P6-final100ct.pdf 
Levy, B.R., Slade, M.D. and Kasl, S.V. (2002a) Longitudinal benefit of positive selfperceptions of aging on functional health. Journal of Gerontology, 57B, P409-P417.

Levy, B.R., Slade, M.D., Kunkel, S.R. and Kasl, S.V. (2002b) Longevity increased by positive self-perceptions of aging. Journal of Personality and Social Psychology, 83 (2), 261-270.

Levy, B.R. (2009). Stereotype embodiment: A psychosocial approach to aging. Current Directions in Psychological Science, 18, 332-336

Levy, S.R. and Macdonald, J.L. (2016) Progress on Understanding Ageism. Journal of Social Issues, 72 (1), 5-25.

Macnicol, J. (2015) Neoliberalising old age. Cambridge: Cambridge University Press.

Murphey, M. and Myers, J.E. (1982) Attitudes of children toward older persons: What they are, what they can be. The School Counselor, 29 (4), 281-289.

O'Cathain, A. and Thomas, K.J. (2004). "Any other comments?" Open questions on questionnaires - a bane or a bonus to research? BMC Medical Research Methodology, 4, 25. [Cited 2018 June 5]. Available from: https://www.ncbi.nlm.nih.gov/pmc/articles/PMC533875/pdf/1471-2288-4-25.pdf

Palmore, E. (2015) Ageism comes of age. Journals of Gerontology: Social Sciences. 70(6): 878-875. 
Pinquart, M., Wenzel, S., and Sörensen, S. (2000) Changes in attitudes among children and elderly adults in intergenerational group work. Educational Gerontology, $26,523-540$.

Ramirez, L. and Palacios-Espinosa, X. (2016) Stereotypes about old age, social support, aging anxiety and evaluations of one's own health. Journal of Social Issues, $72(1), 47-68$.

Riley, M.W. and Riley, J.W. (2000). Age integration: Conceptual and historical background. Gerontologist, 40, 266-270.

Robinson, T., Gustafson, B. and Popovich, M. (2008) Perceptions of negative stereotypes of older people in magazine advertisements: Comparing the perceptions of older adults and college students, Ageing and Society, 28 (2), 233-251.

Robinson, S. and Howatson-Jones, L. (2014) Children's views of older people, Journal of Research in Childhood Education, 28(3), 293-312.

Russell, J., Alexis, D. and Clayton, N. (2010) Episodic future thinking in 3- to 5-yearold children: The ability to think of what will be needed from a different point of view. Cognition, 114 (1), 56-71.

Schafer, M.H. and Shippee, T.P. (2010) Age identity, gender, and perceptions of decline: does feeling older lead to pessimistic dispositions about cognitive aging? Journal of Gerontology: Social Sciences, 65B (1), 91-96. 
Seefeldt, C., Jantz, R.K., Serock, K. and Galper, A. (1977) Children's attitudes toward the elderly: Educational implications, Educational Gerontology, 2 (3), 301310.

Settersten, R. (2005) Linking the two ends of life: what gerontology can learn from childhood studies, Journal of Gerontology: Social Sciences. 60B (4): S179-S180.

Tavakol, M. and Dennick, R. (2011) Making sense of Cronbach's alpha. International Journal of Medical Education, 2, 53-55.

The KIDSCREEN Group Europe (2006) The KIDSCREEN Questionnaires: Quality of life questionnaires for children and adolescents handbook. Lengerich: Pabst Science Publishers.

Thompson, E.H. Jr. and Weaver, A.J. (2016) Making Connections: The Legacy of an Intergenerational Program, Gerontologist, 56 (5), 909-918.

Tulving, E. (2005) Episodic memory and autonoesis: Uniquely human? In H. S. Terrace, and J. Metcalfe (Eds.), The Missing Link in Cognition (pp. 4-56).New York, NY: Oxford University Press.

United Nations Department of Economic and Social Affairs, Population Division (2015). World Population Ageing 2015 (ST/ESA/SER.A/390). [Cited 2017 November 21]. [Cited 2018 June 5]. Available from: 
http://www.un.org/en/development/desa/population/publications/pdf/ageing/WPA201

$\underline{5 \text { Report.pdf }}$

WHO (2017) World Heath Day ' Are you ready? What you need to know about ageing.' [Cited 2018 June 5]. Available from:

http://www.who.int/world-health-day/2012/toolkit/background/en/index3.html

Willetts, D. (2010) The pinch: How the baby boomers stole their children's future. London: Atlantic Books.

\footnotetext{
i Scheffe test for unequal group sizes.

ii Convention is that Cohen's $d$ of 0.20 is small effect; 0.50 is medium effect and 0.80 large effect.
} 